\title{
Alternating Copolymerization of Butadiene with Acrylic Compounds; Monomer-Catalyst Complexes
}

\author{
Junji Furukawa, Yutaka Iseda, ${ }^{* *}$ and Eiichi Kobayashi* \\ Department of Synthetic Chemistry, Kyoto University, Kyoto, Japan.
}

(Received October 22, 1970)

\begin{abstract}
Complex formations among butadiene(BD), acrylic compounds(A) such as acrylonitrile(AN) and methyl methacrylate(MMA), and ethylaluminum dichloride $\left(\mathrm{EtAlCl}_{2}\right.$ or $\left.\mathrm{Al}\right)$ were investigated with cryoscopic measurement, NMR and UV spectroscopies.

From the cryoscopic study on the benzene solution of ethylaluminum dichloride and acrylic monomers such as methacrylonitrile(MAN), acrylonitrile, and methyl methacrylate, the existence of some complexes such as [MAN.Al] $,[\mathrm{AN} \cdot \mathrm{Al}]_{2},[\mathrm{AN} \cdot \mathrm{Al} \cdot \mathrm{AN}]_{\text {, }}$ and $[\mathrm{MMA} \cdot \mathrm{Al}]_{2}$ was estimated. NMR and UV studies suggested the formation of ternary charge-transfer complexes such as [BD $\left.\stackrel{\pi}{ }^{\prime} \cdot \mathrm{MMA} \stackrel{\sigma}{\longrightarrow} \mathrm{Al}\right]$ and [BD $\left.{ }^{\pi} \cdot \cdots \mathrm{AN} \stackrel{\sigma}{\longrightarrow} \mathrm{Al}\right]$.

KEY WORDS Alternating Copolymerization / Butadiene / Acrylonitrile / Methyl Methacrylate / Ethylaluminum Dichloride / Complex / NMR / UV Spectrum / Cryoscopic Study /
\end{abstract}

We have reported on the preparation methods of gel-free alternating copolymers of conjugated diolefins and polar acrylic monomers at rather low temperature such as $0^{\circ} \mathrm{C},{ }^{1,2}$ mechanical properties of the alternating copolymer of butadiene and acrylonitrile, ${ }^{3}$ kinetic studies on the alternating copolymerization of butadiene with acrylonitrile or methyl methacrylate with use of ethylaluminum dichloride-vanadyl trichloride $\left(\mathrm{VOCl}_{3}\right.$ or $\mathrm{V}$ ) catalyst at $0^{\circ} \mathrm{C}_{,}^{4,5}$ and the alternating copolymerization of butadiene with acrylonitrile under UV irradiation in the presence of Lewis acid. ${ }^{6}$

In this paper, the mechanism of the alternating copolymerization of butadiene with acrylonitrile or methyl methacrylate, especially, the complex formations among the monomers and the catalyst will be discussed.

\section{EXPERIMENTAL}

The reaction of butadiene with the acrylic monomer was carried out according to the procedure reported previously. ${ }^{4}$

* Institute for Chemical Research, Kyoto University, Uji, Japan.

** On leave from Tokyo Research Institute, Bridgeston Tire Co., Ltd., Tokyo, Japan.
The cryoscopic measurement on the benzene solution of ethylaluminum dichloride and the acrylic monomer was executed under a nitrogen atmosphere by measuring the depression of the freezing point with use of the Beckmann-type apparatus equipped with a Beckmann thermometer. The mixture was quite homogeneous and the total number of solute molecules per each unit molecule of ethylaluminum dichloride was estimated. The depression ranging from 0.100 to $0.500^{\circ} \mathrm{C}$ was observed at the concentrations of about 20 to $70 \mathrm{mmol}$ of ethylaluminum dichloride/kg-benzene and of about 20 to $130 \mathrm{mmol}$ of acrylic monomer/kg-benzene. ${ }^{7}$

NMR spectrum of the binary or ternary mixture of ethylaluminum dichloride, methyl methacrylate, and benzene was recorded on a $60-\mathrm{MHz}$ Varian Model T-60 NMR spectrometer at room temperature to investigate the interaction among the solutes. Tetramethylsilane was used as an internal standard. The interaction between butadiene and methyl methacrylate admixed with an equimolar amount of ethylaluminum dichloride was examined in dichloromethane at about $-70^{\circ} \mathrm{C}$ and was evaluated by a continuous variation method in the chemical shifts with use of a $60-\mathrm{MHz}$ NMR spectrometer Model JNM-3H-60 manufactured by 
Japan Electron Optics Lab. Co. The dilute dichloromethane solution and tetramethylsilane in a capillary tube as an external standard were sealed in an NMR tube. The total concentration of butadiene and methyl methacrylate was kept constant at $1.57 \mathrm{~mol} / l$, and the concentration of ethylaluminum dichloride was adjusted to that of the latter monomer.

For similar purposes, the UV spectrum at about $-78^{\circ} \mathrm{C}$ was recorded on a Hitachi Model EPS-2 UV spectrometer. The dilute dichloromethane solution of a concentration of about $10^{-2} \mathrm{~mol} / \mathrm{l}$ was sealed in a quartz cell of $1-\mathrm{cm}$ thick under nitrogen atmosphere and the cell was dipped in methyl alcohol cooled by solid carbon dioxide in a quartz-made jar settled in the UV spectrometer.

\section{RESULTS AND DISCUSSION}

In the previous papers, ${ }^{4,5}$ some important features of the alternating copolymerization of butadiene with acrylonitrile or methyl methacrylate with use of the $\mathrm{EtAlCl}-\mathrm{VOCl}_{3}$ catalyst at $0^{\circ} \mathrm{C}$ were reported. The dependence of the polymerization rates on the monomer concentrations can be explained by supposing that the ternary complexes of butadiene, the acrylic monomer, and the aluminum compound are equilibrated with some other complexes of the acrylic monomer and the aluminum compound as follows.

$$
\begin{aligned}
\mathrm{Al}+n \mathrm{~A} \stackrel{K_{1}}{\rightleftarrows}\left(\mathrm{Al} \cdot \mathrm{A}_{n}\right) \cdots(\text { less active })^{8} \\
\mathrm{~A} 1+\mathrm{A}+\mathrm{BD} \stackrel{K_{2}}{\rightleftharpoons}(\mathrm{Al} \cdot \mathrm{A} \cdot \mathrm{BD}) \\
(\mathrm{Al} \cdot \mathrm{A} \cdot \mathrm{BD}) \stackrel{K_{3}}{\rightleftarrows}(\mathrm{Al} \cdot \mathrm{A} \cdot \mathrm{BD})^{*} \cdots \\
(\text { active for polymerization })
\end{aligned}
$$

Here, $K_{1}, K_{2}$, and $K_{3}$ represent the equilibrium constants for the formation of $\left(\mathrm{Al} \cdot \mathrm{A}_{n}\right),(\mathrm{A} 1 \cdot \mathrm{A}$. $\mathrm{BD})$, and $(\mathrm{Al} \cdot \mathrm{A} \cdot \mathrm{BD})^{*}$ complexes, respectively.

The concentration of $(\mathrm{Al} \cdot \mathrm{A} \cdot \mathrm{BD})^{*}$ complex is expressed as follows.

$$
\left[(\mathrm{Al} \cdot \mathrm{A} \cdot \mathrm{BD})^{*}\right]=\frac{K_{2} K_{3}[\mathrm{Al}][\mathrm{A}][\mathrm{BD}]}{1+K_{1}[\mathrm{~A}]^{n}+K_{2}[\mathrm{~A}][\mathrm{BD}]}
$$

When $K_{1} \gg K_{2} \gg 1$

$$
\left[(\mathrm{Al} \cdot \mathrm{A} \cdot \mathrm{BD})^{*}\right]=K_{1}^{-1} K_{2} K_{3}[\mathrm{Al}][\mathrm{A}]^{1-n}[\mathrm{BD}]
$$

and when $K_{2} \gg K_{1} \gg 1$

$$
\left[(\mathrm{Al} \cdot \mathrm{A} \cdot \mathrm{BD})^{*}\right]=K_{3}[\mathrm{Al} 1][\mathrm{A}]^{0}[\mathrm{BD}]^{0}
$$

It is assumed that $K_{1} \gg K_{2}$ for the butadieneacrylonitrile system and $K_{2} \gg K_{1}$ for the butadienemethyl methacrylate system, respectively.

As described above, the kinetic studies suggested the existence of $(\mathrm{Al} \cdot \mathrm{A}),\left(\mathrm{Al} \cdot \mathrm{A}_{n}\right)$, and (Al.A.BD) complexes in the polymerization system.

The complexation of acrylonitrile to ethylaluminum dichloride through the lone-paired electron of the nitrogen atom of the nitrile group was indicated by an IR spectroscopy, ${ }^{9}$ but the coordination number of the acrylic monomer to the aluminum compound in the presence of excess acrylic monomer and the change of electron distribution in the complex caused by the complex formation remain unknown.

To evaluate the coordination number, cryoscopic measurements on the benzene solutions of ethylaluminum dichloride and the acrylic compounds were carried out. As shown in Figure 1, the total number of solute molecules per unit molecule of ethylaluminum dichloride, i.e., $\mathrm{N} / \mathrm{Al}$, was plotted against the number of acrylic monomers added to a unit molecule of ethylaluminum dichloride, i.e., A/Al.

The mixture of ethylaluminum dichloride and methacrylonitrile shows typical changes as indicated in Figure 1 (line acg). At the position of $\mathrm{MAN} / \mathrm{Al}=1 / 1$ a sharp change occurs, before

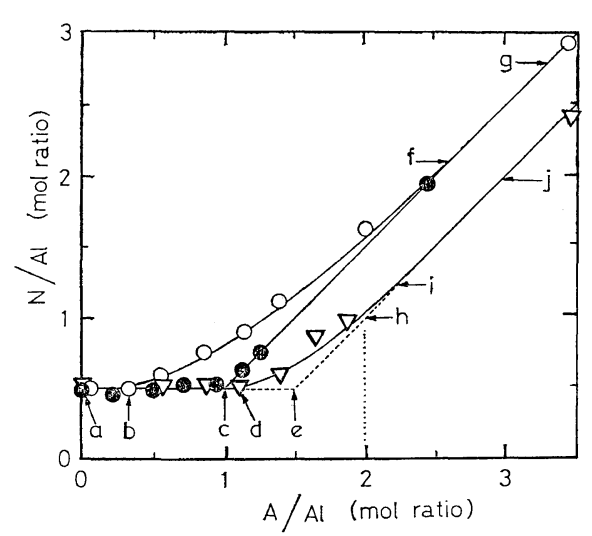

Figure 1. Cryoscopic measurements on $\mathrm{EtAlCl}_{2}-$ A complexes in benzene: MAN; $\bigcirc$, MMA; $\nabla$, AN. A represents MAN, MMA, or AN. 
which N/Al is kept constant at $1 / 2$ and beyond which the increase in $\mathrm{N} / \mathrm{Al}$ is quite equal to that in MAN/Al. These facts mean that in the region of $\mathrm{MAN} / \mathrm{Al}$ being less than $1 / 1$, added MAN is completely complexed with the aluminum compound, while beyond this point further complexation does not occur. Since N/Al is kept constant at $1 / 2$, the complex exists in a dimer form as follows.

$$
\left(\mathrm{EtAlCl}_{2}\right)_{2}+2 \mathrm{MAN} \stackrel{\text { large } K}{\rightleftharpoons}\left(\begin{array}{c}
\mathrm{EtAlCl}_{2} \\
\stackrel{\uparrow}{\mathrm{MAN}}
\end{array}\right)_{2}
$$

The complexation of methyl methacrylate with ethylaluminum dichloride is not discrete, but it can be interpreted that the curve abfg in Figure 1 can be roughly divided into two asymptotic lines, ac and cg. At the point c, a complex of $\left(\mathrm{EtAlCl}_{2} \cdot \mathrm{MMA}\right)_{2}$ would be formed if added methyl methacrylate is completely complexed with the aluminum compound. The complexation of methyl methacrylate with the aluminum compound may not be complete because the saturation takes place not at the point $c$ but at the point $f$. This means an equilibrium constant for the complexation is rather small. The line $\mathrm{fg}$ means the coexistence of $\left(\mathrm{EtAlCl}_{2} \cdot \mathrm{MMA}\right)_{2}$ and free methyl methacrylate. This fact indicates the form of the complex of ethylaluminum dichloride and methyl methacrylate to be $\left(\mathrm{EtAlCl}_{2}\right.$. MMA $)_{2}$ in the presence of excess methyl methacrylate.

In the case of acrylonitrile, the curve adij in Figure 1 would be divided into two asymptotic lines, ae and ej. At the point $\mathrm{c},\left(\mathrm{EtAlCl}_{2} \cdot \mathrm{AN}\right)_{2}$ complex is estimated to be formed, at the point e, $\left\{\left(\mathrm{AN}_{2} \cdot \mathrm{EtAlCl}_{2}\right) \cdot\left(\mathrm{EtAlCl}_{2} \cdot \mathrm{AN}\right)\right\}$ complex would be formed if added acrylonitrile is completely complexed with the aluminum compound. The complexation of acrylonitrile with $\left(\mathrm{EtAlCl}_{2}\right)_{2}$ is considered to be complete, but that of acrylonitrile with $\left(\mathrm{EtAlCl}_{2} \cdot \mathrm{AN}\right)_{2}$ may not be complete since the saturation is observed not at the point $\mathrm{e}$ or $\mathrm{h}$ but at the point i. This means the equilibrium constant for the first complexation is large but that for the second complexation is rather small. The line $\mathrm{ij}$ means the coexistence of both or either of $\left\{\left(\mathrm{AN}_{2} \cdot \mathrm{Al}\right) \cdot(\mathrm{Al} \cdot \mathrm{AN})\right\}$ and/or $\left(\mathrm{Al} \cdot \mathrm{AN}_{2}\right.$ ) complexes with free acrylonitrile. The coordination of strong Lewis bases such as pyridine, tetrahydrofuran, and triethylamine to alkylaluminum dichloride induced the dissociation of the dimeric aluminum compound to the monomeric one. ${ }^{10}$ Therefore, the form of the complex of acrylonitrile and ethylaluminum dichloride in the presence of excess acrylonitrile is rather estimated to be $\left(\mathrm{Al} \cdot \mathrm{AN}_{2}\right)$.

In general, it can be said that ethylaluminum dichloride is capable of complexing with one or two moles of acrylic monomers according to the nature of acrylic monomer, and the equilibrium constant for the nitrile compound is large, whereas that for the carboxylic acid ester is rather small. The higher complexation sometimes results in accompanying dissociation of the dimeric aluminum compound.

NMR spectroscopy provided the evidence of the formation of some complexes in a system involving zinc chloride, acrylic monomer, and benzene. ${ }^{11}$ In the case of a system involving ethylaluminum dichloride, NMR spectra of ethyl protons of ethylaluminum dichloride afford additional information on the complex formation. As shown in Table I, methyl methacrylate

Table I. Interaction between $\mathrm{MMA}$ and $\mathrm{EtAlCl}_{2}$ (NMR at room temperature) ${ }^{\mathrm{a}}$

\begin{tabular}{|c|c|c|c|c|c|c|c|c|}
\hline \multirow{2}{*}{ No. } & \multirow{2}{*}{$\begin{array}{l}\text { Mixture, } \\
\text { molar ratio }\end{array}$} & \multicolumn{4}{|c|}{ MMA } & \multicolumn{3}{|c|}{$\mathrm{EtAlCl}_{2}$} \\
\hline & & $\mathrm{H}_{\mathrm{e}}, \tau$ & $\mathbf{H}_{\mathrm{t}}, \tau$ & $\mathrm{OCH}_{3}, \tau$ & $\mathrm{CH}_{3}, \tau$ & $\mathrm{CH}_{2}, \tau$ & $\mathrm{CH}_{3}, \tau$ & $\delta \mathrm{CH}_{3}-\delta \mathrm{CH}_{2}, \mathrm{~Hz}$ \\
\hline 1 & MMA & 3.92 & 4.43 & 6.28 & 8.10 & - & - & - \\
\hline 2 & $\mathrm{Et} \mathrm{AlCl}_{2}$ & - & - & - & - & 9.47 & 8.88 & -35 \\
\hline 3 & $\begin{array}{c}\text { MMA-EtAlCl } \\
(1: 1)\end{array}$ & 3.27 & 3.72 & 5.75 & 7.90 & 9.88 & 8.98 & -54 \\
\hline
\end{tabular}

a Here, $\begin{aligned} & \mathrm{H}_{t} \\ & \mathrm{H}_{\mathrm{c}}\end{aligned}>\mathrm{C}=\mathrm{C}\left\langle\mathrm{O} / \mathrm{C}-\mathrm{OCH}_{3}\right.$. TMS was used as an internal standard (neat). 


\section{J. Furukawa, Y. Iseda, and E. Kobayashi}

indicated absorptions at 3.92, 4.43, 6.28, and $8.10 \tau$, which are assignable to vinyl protons of cis and trans with respect to the carbonyl group $\left(\mathrm{H}_{\mathrm{c}}\right.$ and $\left.\mathrm{H}_{\mathrm{t}}\right)$, methoxy and methyl protons respectively. The ethyl group in ethylaluminum dichloride showed absorptions at 8.88 and $9.47 \tau$ assignable to methyl and methylene protons, respectively. The value of $\delta_{\mathrm{CH}_{3}}-\delta_{\mathrm{CH}_{2}}$ for the aluminum compound was $-35 \mathrm{~Hz}$. In the $1: 1$ mixture of methyl methacrylate and ethylaluminum dichloride, considerable shifts to the lower magnetic field were observed for $H_{c}$ and $\mathrm{H}_{\mathrm{t}}$, i.e., $39 \mathrm{~Hz}$ and $43 \mathrm{~Hz}$, respectively. At the same time, methyl and methylene protons of ethylaluminum dichloride showed 'shifts to the higher magnetic field, and the value of $\delta_{\mathrm{CH}_{3}}-$ $\delta_{\mathrm{CH}_{2}}$ was $-54 \mathrm{~Hz}$. Similar decrease in the above value for triethylaluminum was observed on addition of diethyl ether. ${ }^{12}$ The decrease was considered to indicate a decrease in an apparent electronegativity of the aluminum atom caused by coordination with the ether. In other words, the donation of electron from the oxygen was estimated to increase the electron density of the metal and to decrease its tendency to share the electrons of the carbon-metal bond. ${ }^{12}$ A similar mechanism may be inferred for the decrease in an electron-withdrawing power of the aluminum atom of ethylaluminum dichloride by coordination to methyl methacrylate from the observed decrease in the value of $\delta_{\mathrm{CH}_{3}}-\delta_{\mathrm{CH}_{2}}$ caused by addition of methyl methacrylate.

These observations suggest that the electron of methyl methacrylate is withdrawn to the aluminum atom to some extent at the expense of electronegativity of the aluminum atom. These facts are compatible with the formation of the complex of ethylaluminum dichloride with the acrylic monomer assumed in the cryoscopic study.

As indicated in Table II, the addition of benzene to methyl methacrylate induces the shifts of the $H_{c}$ and $H_{t}$ to the higher magnetic field. The shifts in the presence of ethylaluminum dichloride were +10 and $+19 \mathrm{~Hz}$, respectively, while those in the absence of the aluminum compound were \pm 0 and $+9 \mathrm{~Hz}$, respectively. These facts suggest that the complexation of methyl methacrylate with ethylaluminum dichloride induces the interaction between benzene and methyl methacrylate. On the other hand, the absorptions of methyl and methylene protons of ethylaluminum dichloride in the $1: 1: 1 \mathrm{mix}-$ ture of benzene, methyl methacrylate, and ethylaluminum dichloride shifted slightly to the lower magnetic field than those in the 1:1 mixture of methyl methacrylate and ethylaluminum dichloride, but the value of $\delta_{\mathrm{CH}_{3}}-\delta_{\mathrm{CH}_{2}}$ for the former ternary mixture was nearly equal to that for the latter binary mixture. These indicate no influence of benzene on electronegativity of the aluminum atom in the ternary mixture. From these facts benzene is estimated to coordinate not directly to ethylaluminum dichloride but to methyl methacrylate complexed with the aluminum compound.

The direct evidence for the formation of a ternary complex of butadiene, acrylic monomer,

Table II. Effect of benzene on the NMR of the mixture of MMA and $\mathrm{EtAlCl}_{2}$ (NMR at room temperature $)^{\mathrm{a}}$

\begin{tabular}{|c|c|c|c|c|c|c|c|c|c|}
\hline \multirow{2}{*}{ No. } & \multirow{2}{*}{$\begin{array}{l}\text { Mixture, } \\
\text { molar ratio }\end{array}$} & \multirow{2}{*}{$\frac{\mathrm{Bz}}{\mathrm{H}, \tau}$} & \multicolumn{4}{|c|}{ MMA } & \multicolumn{3}{|c|}{ EtAlCl${ }_{2}$} \\
\hline & & & $\mathbf{H}_{\mathrm{c}}, \tau$ & $\mathrm{H}_{\mathrm{t}}, \tau$ & $\mathrm{OCH}_{3}, \tau$ & $\mathrm{CH}_{3}, \tau$ & $\mathrm{CH}_{2}, \tau$ & $\mathrm{CH}_{3}, \tau$ & $\delta_{\mathrm{CH}_{3}}-\delta_{\mathrm{CH}_{2}}, \mathrm{~Hz}$ \\
\hline 1 & MMA & - & 3.92 & 4.43 & 6.28 & 8.10 & - & - & 一 \\
\hline 4 & $\mathrm{Bz}$-MMA $(1: 1)$ & 2.72 & 3.92 & 4.58 & 6.43 & 8.13 & - & - & - \\
\hline 3 & $\begin{array}{l}\text { MMA-EtAlCl } \\
(1: 1)\end{array}$ & - & 3.27 & 3.72 & 5.75 & 7.90 & 9.88 & 8.98 & -54 \\
\hline 5 & $\begin{array}{c}\mathrm{Bz}-\mathrm{MMA}-\mathrm{EtAlCl}_{2} \\
(1: 1: 1)\end{array}$ & 2.70 & 3.43 & 4.03 & 6.08 & 8.12 & 9.82 & 8.90 & -55 \\
\hline 6 & $\mathrm{Bz}-\mathrm{EtAlCl}_{2}(1: 1)$ & 2.79 & - & - & - & - & 9.68 & 8.97 & -43 \\
\hline
\end{tabular}

a Here, Bz represents benzene. TMS was used as an internal standard (neat). 


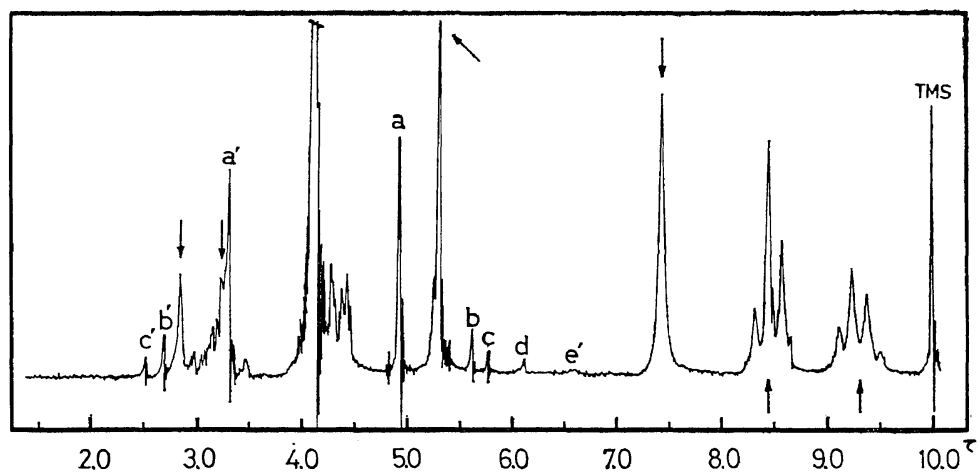

Figure 2. NMR spectrum of a dichloromethane solution of a mixture of butadiene, methyl methacrylate and ethylaluminum dichloride at about $-70^{\circ} \mathrm{C}:[\mathrm{BD}] /[\mathrm{MMA}]=2 / 3$, [MMA]/[Al] =1/1 (molar ratio); a, $\mathrm{a}^{\prime} \mathrm{b}, \mathrm{b}^{\prime} \mathrm{c}$, and $\mathrm{c}^{\prime}$, side bands of $\mathrm{CH}_{2} \mathrm{Cl}_{2} ; \mathrm{d}$ and $\mathrm{d}^{\prime}$, side bands of $\mathrm{OCH}_{3}$; e and $\mathrm{e}^{\prime}$, side bands of $\mathrm{CH}_{3}$ of $\mathrm{MMA}$.

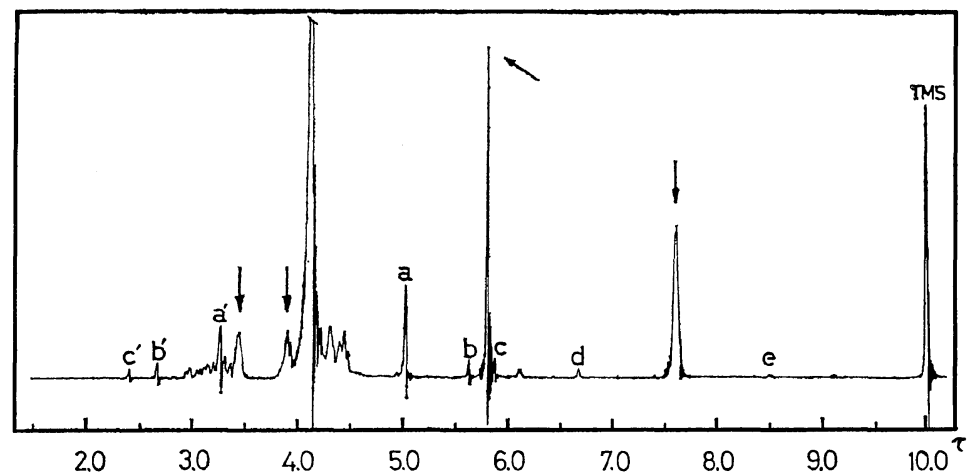

Figure 3. NMR spectrum of a dichloromethane solution of a mixture of butadiene and methyl methacrylate at about $-70^{\circ} \mathrm{C} ;[\mathrm{BD}] /[\mathrm{MMA}]=2 / 3$ (molar ratio).

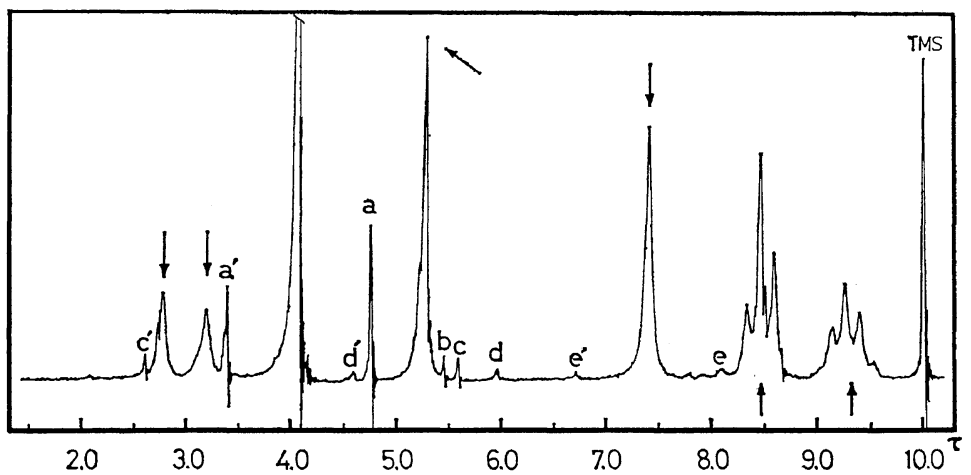

Figure 4. NMR spectrum of a dichloromethane solution of a mixture of methyl methacrylate and ethylaluminum dichloride at about $-70^{\circ} \mathrm{C} ;[\mathrm{MMA}] /[\mathrm{Al}]=1 / 1$ (molar ratio). 
Table IIIa. NMR of $\mathrm{BD}-\left(\mathrm{MMA}-\mathrm{Et} \mathrm{AlCl}_{2}\right)$ mixture in $\mathrm{CH}_{2} \mathrm{Cl}_{2}$ at about $-70^{\circ} \mathrm{C}$ (Continuous variation) $)^{\mathrm{a}}$

\begin{tabular}{|c|c|c|c|c|c|c|c|c|}
\hline \multirow[b]{2}{*}{ No. } & \multirow{2}{*}{$\frac{\text { Mixture }}{\begin{array}{c}\mathrm{BD}:(\mathrm{MMA}-\mathrm{Al}) \\
\text { molar ratio }\end{array}}$} & \multicolumn{4}{|c|}{ MMA } & \multicolumn{3}{|c|}{$\mathrm{EtAlCl}_{2}$} \\
\hline & & $\mathbf{H}_{\mathrm{c}}, \tau$ & $\mathrm{H}_{\mathrm{t}}, \tau$ & $\mathrm{OCH}_{3}, \tau$ & $\mathrm{CH}_{3}, \tau$ & $\mathrm{CH}_{3}, \tau$ & $\mathrm{CH}_{2}, \tau$ & $\delta \mathrm{CH}_{3}-\delta \mathrm{CH}_{2}, \mathrm{~Hz}$ \\
\hline 1 & $0: 100$ & 2.77 & 3.19 & 5.25 & 7.41 & 8.47 & 9.33 & -52 \\
\hline 2 & $25: 75$ & 2.78 & 3.20 & 5.27 & 7.42 & 8.45 & 9.31 & -52 \\
\hline 3 & $40: 60$ & 2.81 & 3.22 & 5.30 & 7.44 & 8.46 & 9.32 & -52 \\
\hline 4 & $50: 50$ & 2.83 & 3.25 & 5.32 & 7.46 & 8.48 & 9.34 & -52 \\
\hline 5 & $60: 40$ & 2.84 & $-^{\mathrm{b}}$ & 5.33 & 7.47 & 8.48 & 9.34 & -52 \\
\hline 6 & $75: 25$ & $-^{b}$ & $-b$ & 5.32 & 7.46 & 8.46 & 9.32 & -52 \\
\hline 7 & $90: 10$ & $-b$ & $-b$ & 5.31 & 7.45 & 8.45 & 9.31 & -52 \\
\hline
\end{tabular}

a Here, $[\mathrm{BD}]+[\mathrm{MMA}-\mathrm{Al}]=1.57 \mathrm{~mol} / l$. TMS was used as an external standard. The accuracy of the chemical shifts is \pm 0.01 .

b Being overlapped by the absorption of butadiene.

Table IIIb. $\Delta \tau_{\mathrm{c}}$ and $\Delta \tau_{\mathrm{c}} \cdot[\mathrm{MMA}]$ for $\mathrm{MMA}^{\mathrm{a}}$

\begin{tabular}{|c|c|c|c|c|c|c|c|c|c|}
\hline \multirow[b]{2}{*}{ No. } & \multirow{2}{*}{$\frac{\text { Mixture }}{\begin{array}{c}\mathrm{BD}:(\mathrm{MMA}-\mathrm{Al}) \\
\text { molar ratio }\end{array}}$} & \multicolumn{4}{|c|}{$\Delta \tau_{\mathrm{c}}$ for $\mathrm{MMA}$} & \multicolumn{4}{|c|}{$\Delta \tau_{\mathrm{c}} \cdot[\mathrm{MMA}] \times 10^{2}$} \\
\hline & & $\mathrm{H}_{\mathrm{c}}$ & $\mathrm{H}_{\mathrm{t}}$ & $\mathrm{OCH}_{3}$ & $\mathrm{CH}_{3}$ & $\mathrm{H}_{\mathrm{c}}$ & $\mathrm{H}_{\mathrm{t}}$ & $\mathrm{OCH}_{3}$ & $\mathrm{CH}_{3}$ \\
\hline 2 & $25: 75$ & 0.01 & 0.01 & 0.02 & 0.01 & 1.2 & 1.2 & 2.4 & 1.2 \\
\hline 3 & $40: 60$ & 0.04 & 0.03 & 0.05 & 0.03 & 3.7 & 2.8 & 4.7 & 2.8 \\
\hline 4 & $50: 50$ & 0.06 & 0.06 & 0.07 & 0.05 & 4.7 & 4.7 & 5.5 & 4.0 \\
\hline 5 & $60: 40$ & 0.07 & - & 0.08 & 0.06 & 4.4 & - & 5.0 & 3.8 \\
\hline 6 & $75: 25$ & - & - & 0.07 & 0.05 & - & - & 2.7 & 2.0 \\
\hline 7 & $90: 10$ & - & - & 0.06 & 0.04 & - & - & 1.0 & 0.6 \\
\hline
\end{tabular}

a Here, $\Delta \tau_{\mathrm{c}}=\tau-\tau_{0} ; \tau_{0}$, chemical shift for $1: 1 \mathrm{MMA}-\mathrm{EtAlCl}_{2}$ mixture.

Table HIIc. $\Delta \tau_{\mathrm{c}}$ for $\mathrm{EtAlCl} \mathrm{Al}_{2}$

\begin{tabular}{ccrcc}
\hline & \multicolumn{2}{c}{ Mixture } & & \multicolumn{2}{c}{$\Delta \tau_{\mathrm{c}}$ for $\mathrm{EtAlCl}_{2}$} \\
\cline { 5 - 5 } No. & $\begin{array}{c}\text { BD : (MMA-Al) } \\
\text { molar ratio }\end{array}$ & & $\mathrm{CH}_{3}$ & $\mathrm{CH}_{3}$ \\
\hline 2 & $25: 75$ & & -0.02 & -0.02 \\
3 & $40: 60$ & & -0.01 & -0.01 \\
4 & $50: 50$ & & +0.01 & +0.01 \\
5 & $60: 40$ & & +0.01 & +0.01 \\
6 & $75: 25$ & & -0.01 & -0.01 \\
7 & $90: 10$ & -0.02 & -0.02 \\
\hline
\end{tabular}

and ethylaluminum dichloride was given by NMR spectroscopy at extremely low temperature. Typical NMR spectra of the dichloromethane solution of butadiene with methyl methacrylate in the presence or the absence of ethylaluminum dichloride and that of an equimolar mixture of methyl methacrylate and ethylaluminum dichloride are shown in Figures 2, 3, and 4. A sig- nificant interaction between butadiene and methyl methacrylate was not detected out in the absence of ethylaluminum dichloride. On the other hand, in the presence of the aluminum compound, the continuous variation curves for the changes in the chemical shifts of $\alpha$-methyl and methoxy protons of methyl methacrylate afforded maximum values both at an 1:1 molar ratio of butadiene to methyl methacrylate as shown in Table III and Figure 5. The changes in the chemical shifts of $\mathrm{H}_{\mathrm{c}}$ and $\mathrm{H}_{\mathrm{t}}$ of methyl methacrylate and of methyl and methylene protons of ethylaluminum dichloride also showed a similar tendency as shown in Table III.

From these facts the formation of $1: 1$ complex of butadiene and methyl methacrylate in the presence of ethylaluminum dichloride is considered to be acceptable.

The interaction between butadiene and methyl methacrylate complexed with ethylaluminum 


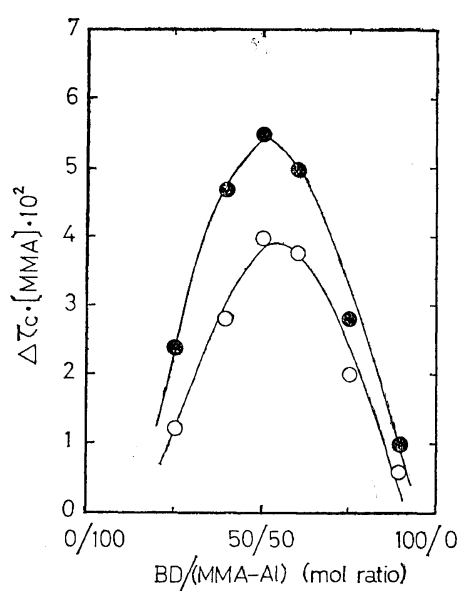

Figure 5. Continuous variation curves for the change in the chemical shifts of $\mathrm{OCH}_{3}$ and $\mathrm{CH}_{3}$ of MMA in the BD-(1:1 MMA-Et $\left.\mathrm{AlCl}_{2}\right)$ system at about $-70^{\circ} \mathrm{C}$ :, $\mathrm{OCH}_{3} ; \bigcirc, \mathrm{CH}_{3}$.

dichloride was also estimated from the UV spectra as shown in Figure 6, which seems to indicate the formation of a charge-transfer complex having an absorption band at about 340 $\mathrm{m} \mu$. Similar interaction between butadiene and acrylonitrile complexed with ethylaluminum dichloride was also observed as shown in the same Figure. Detailed UV study is now in progress.

These results of the cryoscopic and spectroscopic investigations support the existence of $(\mathrm{Al} \cdot \mathrm{A}),\left(\mathrm{Al} \cdot \mathrm{A}_{n}\right)$, and $(\mathrm{Al} \cdot \mathrm{A} \cdot \mathrm{BD})$ complexes in the polymerization system, which were assumed by the kinetic studies. ${ }^{4,5}$ On the other hand, the magnitude of equilibrium constants can not be estimated precisely by these methods. The cryoscopic measurements show the relatively high value for the $\mathrm{AN}-\mathrm{Al}$ system, and the low value for the MMA-Al system. A ternary system of BD-MMA-Al can actually exist but its equilibrium constant does not seem to be so high as expected in eq 7 according to other experiments on a complex of styrene-acrylonitrile$\mathrm{ZnCl}_{2}$.

In this connection the assumption proposed by Zubov, et al., ${ }^{14}$ is noteworthy in that the complex exists at the growing polymer radical in the case of the homopolymerization of methyl methacrylate in the presence of aluminum bromide. In the alternating copolymerization a similar concept may be useful, but the complex formation at the polymer end may take place not only between the growing AN radical and $\mathrm{BD}$ or between the growing $\mathrm{BD}$ radical and $\mathrm{AN}$, but also among the growing AN radical, BD and AN. In other words, there are two possibilities for the alternating copolymerizations, one is the alternating coordination of two monomers to the polymer-end radical and the other is the equimolar simultaneous coordidation of two monomers to the growing radical. However, the former mechanism is not so effective for the formation of the highly regular alternating copolymer as compared with the latter mechanism. Moreover, it is rather difficult to explain in

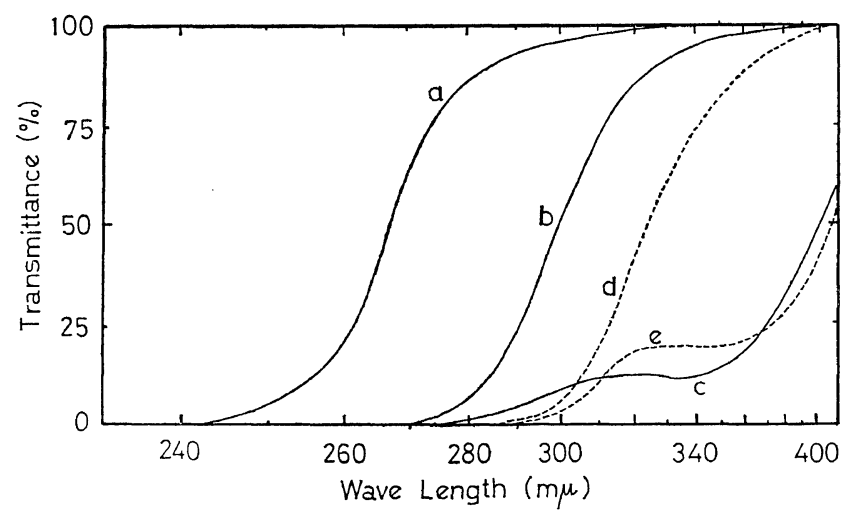

Figure 6. UV spectra of dichloromethane solution at about $-78^{\circ} \mathrm{C}$ : [MMA]

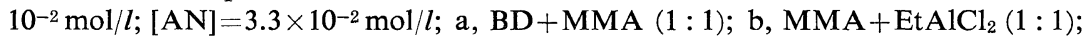

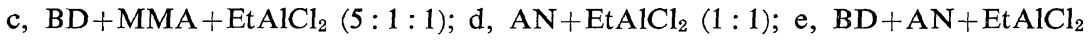
$(5: 1: 1)$. 
terms of the former mechanism the reason for the fact that polymerization of butadiene does not occur after exhausting AN monomer in the system containing excess amount of butadiene monomer. However, the problems whether or not a charge-transfer complex of butadiene and acrylic monomer is resposible for the alternating copolymerization and whether or not the chargetransfer complex is formed only at the growing radical are left unsettled.

\section{REFERENCES}

1. J. Furukawa and Y. Iseda, J. Polym. Sci., Part B, 7, 47 (1969).

2. J. Furukawa, Y. Iseda, K. Haga, and N. Kataoka, J. Polym. Sci., Part A-1, 8, 1147 (1970).

3. J. Furukawa, Y. Iseda, K. Haga, N. Kataoka, T. Yoshimoto, T. Imamura, Y. Shido, A. Miyagi, K. Tanaka, and K. Sakamoto, $J$. Polym. Sci., Part B, 7, 561 (1969).

4. J. Furukawa, E. Kobayashi, and Y. Iseda, Polymer J., 1, 155 (1970).
5. J. Furukawa, E. Kobayashi, Y. Iseda, and Y. Arai, Polymer J., 1, 442 (1970).

6. J. Furukawa, E. Kobayashi, and Y. Iseda, $J$. Polym. Sci., Part B, 8, 47 (1970).

7. J. Furukawa, Y. Iseda, and E. Kobayashi, $J$. Polym. Sci., Part B, 8, 631 (1970).

8. J. Furukawa, E. Kobayashi, and J. Yamauchi, Polymer J., in press.

9. M. Hirooka, H. Yabuuchi, S. Morita, S. Kawasumi, and S. Nakaguchi J. Polym. Sci., Part B, 5, 47 (1967).

10. A. Zambelli, A. L. Segre, A. Marinangeli, and G. Gatti, Chim. Ind. (Milan), 48, 1 (1966).

11. H. Hirai, S. Okazawa, T. Ikegami, and S. Makishima, J. Fac. Eng., Tokyo Univ., B, 29, 115 (1967).

12. S. Brownstein, B. C. Smith, G. Ehrich, and A. W. Lawbengayer, J. Amer. Chem. Soc., 81, 3826 (1959).

13. T. Ikegami and H. Hirai, J. Polym. Sci., Part $A-1,8,195$ (1970).

14. V. P. Zubov, M. B. Lachinov, L. I. Valuev, V. B. Golubev, V. A. Kabanov, and V. A. Kargin, Vysokomol. Soedin., Ser. B, 9, 667 (1967). 